\title{
Episodic Social Stress-Escalated Cocaine Self-Administration: Role of Phasic and Tonic Corticotropin Releasing Factor in the Anterior and Posterior Ventral Tegmental Area
}

\author{
Elizabeth N. Holly, ${ }^{1,2}$ Christopher 0. Boyson, ${ }^{1}$ Sandra Montagud-Romero, ${ }^{3}$ Dirson J. Stein, ${ }^{4}$ Kyle L. Gobrogge, ${ }^{1}$ \\ Joseph F. DeBold, ${ }^{1}$ and ${ }^{D}$ Klaus A. Miczek $^{1,5}$ \\ ${ }^{1}$ Department of Psychology, Tufts University, Medford, Massachusetts 02155, ${ }^{2}$ McGovern Institute for Brain Research and Department of Brain and \\ Cognitive Sciences, Massachusetts Institute of Technology, Cambridge, Massachusetts 02139, ${ }^{3}$ Unidad de Investigación Psicobiología de las \\ Drogodependencias, Departamento de Psicobiología, Facultad de Psicología, Universitat de València, València, Spain 46010, ${ }^{4}$ Programa de Pós-Graduação \\ em Ciências Médicas, Psiquiatria, Universidade Federal do Rio Grande do Sul, Porto Alegre, RS, Brazil 90050, and ${ }^{5}$ Departments of Neuroscience and \\ Pharmacology, Tufts University School of Medicine, Boston, Massachusetts 02111
}

Intermittent social defeat stress escalates later cocaine self-administration. Reward and stress both activate ventral tegmental area (VTA) dopamine neurons, increasing downstream extracellular dopamine concentration in the medial prefrontal cortex and nucleus accumbens. The stress neuropeptide corticotropin releasing factor (CRF) and its receptors (CRF-R1, CRF-R2) are located in the VTA and influence dopaminergic activity. These experiments explore how CRF release and the activation of its receptors within the VTA both during and after stress influence later cocaine self-administration in rats. In vivo microdialysis of CRF in the VTA demonstrated that CRF is phasically released in the posterior VTA (pVTA) during acute defeat, but, with repeated defeat, CRF is recruited into the anterior VTA (aVTA) and CRF tone is increased in both subregions. Intra-VTA antagonism of CRF-R1 in the pVTA and CRF-R2 in the aVTA during each social defeat prevented escalated cocaine self-administration in a $24 \mathrm{~h}$ "binge." VTA CRF continues to influence cocaine seeking in stressed animals long after social defeat exposure. Unlike nonstressed controls, previously stressed rats show significant cocaine seeking after $15 \mathrm{~d}$ of forced abstinence. Previously stressed rats continue to express elevated CRF tone within the VTA and antagonism of pVTA CRF-R1 or aVTA CRF-R2 reverses cocaine seeking. In conclusion, these experiments demonstrate neuroadaptive changes in tonic and phasic CRF with repeated stress, that CRF release during stress may contribute to later escalated cocaine taking, and that persistently elevated CRF tone in the VTA may drive later cocaine seeking through increased activation of pVTA CRF-R1 and aVTA CRF-R2.

Key words: cocaine seeking; cocaine self-administration; corticotropin releasing factor; social defeat; stress; ventral tegmental area

Significance Statement

Corticotropin releasing factor (CRF) within the ventral tegmental area (VTA) has emerged as a likely candidate molecule underlying the fundamental link between stress history and escalated drug self-administration. However, the nature of CRF release in the VTA during acute and repeated stress, as well as its role in enduring neuroadaptations driving later drug taking and seeking, are poorly understood. These experiments explore how CRF is released and interacts with its receptors in specific regions of the VTA both during and after stress to fuel later escalated cocaine taking and seeking behavior. Understanding these acute and persistent changes to the VTA CRF system may lead to better therapeutic interventions for addiction.

\section{Introduction}

A history of stress has long been associated with enhanced susceptibility to the initiation, escalation, and relapse of drug use in both preclinical and clinical populations (Erb et al., 1996; Sinha, 2008). In particular, intermittent social defeat stress in rats engenders long lasting neuroadaptations, resulting in behavioral and dopaminergic cross-sensitization to cocaine, accelerated ac- 
quisition of cocaine self-administration, increased breakpoints on a progressive ratio schedule of reinforcement, and escalated cocaine self-administration in a $24 \mathrm{~h}$ "binge" (Miczek and Mutschler, 1996; Tidey and Miczek, 1997; Covington and Miczek, 2001; Holly et al., 2012; Boyson et al., 2014). Understanding how stress initiates a cascade of neural processes in stress and cocaine sensitive systems, as well as the enduring neuroadaptations, may lead to improved targets for therapeutic intervention. It is particularly significant to investigate a neural point of intersection whereby stress and reward mechanisms may interact to potentiate later behavior.

The ventral tegmental area (VTA) notably stands out due to its prominent role in reward-related behavior. However, in addition to its integral role in reward processing, the VTA is also highly responsive to stress/aversion. Dopamine neurons within the VTA are heterogeneous in cytoarchitecture, electrophysiological characteristics, dopaminergic content, and afferent/efferent connectivity (Ikemoto, 2007; Lammel et al., 2014; Holly and Miczek, 2016) and morphological heterogeneity may extend to function as well. Of particular functional importance is heterogeneity between VTA subregions along the anterior/posterior axis. Drugs of abuse are self-administered into the posterior (pVTA), but not anterior (aVTA), portions of the VTA (for review, see Ikemoto, 2007). Rostrocaudal distinctions in VTA function also extend to aversion. A discrete population of dopamine neurons in the pVTA, but not the aVTA, is rapidly and potently excited by acute foot shock (Brischoux et al., 2009).

One potential mediator of stress-induced changes in VTA dopamine neuron activity is the stress neuropeptide corticotropin releasing factor (CRF). Due to their key function in the initiation of the physiological stress response, CRF and its receptors (CRF-R1 and CRF-R2) may play an important role in the behavioral and neural interactions of stress and reward. Although one primary role of CRF is the initiation of the hypothalamic-pituitary-adrenal axis stress response, CRF is also found in widespread extrahypothalamic regions, including the VTA (Swanson et al., 1983). CRF actions on CRF-Rs within the VTA directly and indirectly influence the mesolimbic dopamine system. CRF rapidly increases VTA dopamine neuron firing rate (Korotkova et al., 2006), which is at least partially dependent on postsynaptic CRF-R1 activation (Wanat et al., 2008). Postsynaptic CRF-R2 activation also enhances VTA dopaminergic neuronal excitability through transient potentiation of NMDA currents and metabotropic glutamate receptor current (Fiorillo and Williams, 1998; Ungless et al., 2003). Together, acute activation of VTA CRF-R1 and CRF-R2 leads to increased dopamine neuronal activity, which may in turn cause long-lasting synaptic neural and behavioral adaptations.

Activation of both CRF-R1 and CRF-R2 in the VTA during stress is necessary for the induction of later behavioral and neural cross-sensitization to cocaine and escalated cocaine selfadministration (Boyson et al., 2014). However, the nature of CRF release in the VTA and long-lasting adaptations within the CRF system as a result of repeated stress remain to be determined. As yet, it is unclear whether CRF is phasically released into the VTA during repeated stress, which VTA subregion CRF is exerting its actions, and whether there are neuroadaptive changes in CRF

Correspondence should be addressed to Elizabeth Holly, PhD, McGovern Institute for Brain Research and Department of Brain and Cognitive Sciences, Massachusetts Institute of Technology, 46-2171A, 77 Massachusetts Ave., Cambridge, MA 02139.E-mail: eholly@mit.edu.

DOI:10.1523/JNEUROSCI.2232-15.2016

Copyright $\odot 2016$ the authors $\quad 0270-6474 / 16 / 364094-13 \$ 15.00 / 0$
Table 1. Group sizes

\begin{tabular}{|c|c|c|c|c|}
\hline Experiment & Group & Drug & Target & $n$ \\
\hline \multirow[t]{4}{*}{ 1. Microdialysis for CRF in the VTA during stress } & Nonstressed & $\mu D$ & aVTA & $5,5^{a}$ \\
\hline & Nonstressed & $\mu D$ & pVTA & 5,5 \\
\hline & Stressed & $\mu D$ & aVTA & 5,5 \\
\hline & Stressed & $\mu D$ & pVTA & 5,6 \\
\hline \multirow{12}{*}{$\begin{array}{l}\text { 2. Role of VTA CRF during stress on later } \\
\text { cocaine taking }\end{array}$} & Nonstressed & $\mathrm{aCSF}$ & aVTA & 6 \\
\hline & Nonstressed & $\mathrm{aCSF}$ & pVTA & 7 \\
\hline & Nonstressed & $C P$ & aVTA & 4 \\
\hline & Nonstressed & $C P$ & pVTA & 4 \\
\hline & Nonstressed & $A 2 B$ & aVTA & 4 \\
\hline & Nonstressed & $A 2 B$ & pVTA & 9 \\
\hline & Stressed & $\mathrm{aCSF}$ & aVTA & 4 \\
\hline & Stressed & $\mathrm{aCSF}$ & pVTA & 7 \\
\hline & Stressed & $C P$ & aVTA & 5 \\
\hline & Stressed & $C P$ & pVTA & 5 \\
\hline & Stressed & $A 2 B$ & aVTA & 4 \\
\hline & Stressed & $A 2 B$ & pVTA & 5 \\
\hline \multirow{16}{*}{$\begin{array}{l}\text { 3. Role of VTA CRF after stress on cocaine } \\
\text { seeking after abstinence }\end{array}$} & Nonstressed & $\mathrm{aCSF}$ & aVTA & 4 \\
\hline & Nonstressed & $\mathrm{aCSF}$ & pVTA & 4 \\
\hline & Nonstressed & $C P$ & aVTA & 6 \\
\hline & Nonstressed & $\mathrm{CP}$ & pVTA & 4 \\
\hline & Nonstressed & $A 2 B$ & aVTA & 4 \\
\hline & Nonstressed & $\mathrm{A} 2 \mathrm{~B}$ & pVTA & 4 \\
\hline & Nonstressed & $(\mu \mathrm{D})$ & aVTA & 3 \\
\hline & Nonstressed & $(\mu \mathrm{D})$ & pVTA & 4 \\
\hline & Stressed & $\mathrm{aCSF}$ & aVTA & 5 \\
\hline & Stressed & $\mathrm{aCSF}$ & pVTA & 4 \\
\hline & Stressed & $C P$ & aVTA & 4 \\
\hline & Stressed & $\mathrm{CP}$ & pVTA & 4 \\
\hline & Stressed & $A 2 B$ & aVTA & 5 \\
\hline & Stressed & $\mathrm{A} 2 \mathrm{~B}$ & pVTA & 4 \\
\hline & Stressed & $(\mu \mathrm{D})$ & aVTA & 3 \\
\hline & Stressed & $(\mu \mathrm{D})$ & pVTA & 4 \\
\hline
\end{tabular}

Total $N=151$.

${ }^{a}$ First number represents number included in analysis of day 1 ; second number represents number included for day 10 .

release within the VTA with repeated stress exposure-all of which may be responsible for stress-escalated drug use. Using in vivo microdialysis, we first explored the nature of phasic and tonic CRF increases in the VTA during acute and repeated stress (Experiment 1). Next, we investigated whether CRF actions on its receptors in the aVTA and pVTA during stress are necessary for subsequent escalated cocaine self-administration (Experiment 2). Finally, we investigated whether persistent alterations in CRF/ CRF-R interactions within the aVTA and pVTA play a role in later escalated cocaine-seeking behavior long after stress exposure (Experiment 3).

\section{Materials and Methods}

\section{General methods and design}

Subjects

Male Long-Evans rats $(N=151$, Experiment $1, n=21$; Experiment 2, $n=64$; Experiment 3, $n=66$; see Table 1 for group sizes; rats were obtained from Charles River) weighed 225-250 g upon arrival and were individually housed in custom-built acrylic chambers $(30 \times 20.5 \times 24.5$ $\mathrm{cm}$ ) and given food and water ad libitum. Rats were allowed to habituate to the vivarium for at least 1 week before surgery or experimental manipulations. Stimulus "resident" rats were housed in male-female pairs in large stainless steel cages $(71 \times 46 \times 46 \mathrm{~cm})$ in a separate room as described previously (Miczek, 1979). All procedures were approved by the Tufts University Institutional Animal Care and Use Committee following the guidelines set forth in the Guide for Care and Use of Laboratory Animals (National Research Council, 2011). 


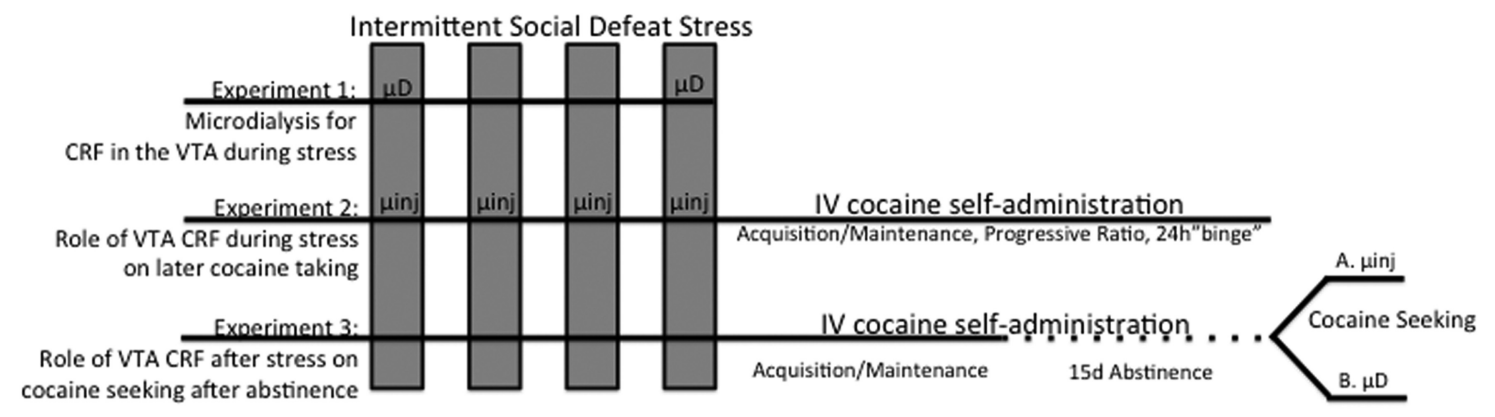

Figure 1. Experimental design. Social defeat (SD, gray bars) occurred on days 1, 4,7, and 10. In Experiment 1, microdialysis (UD) for CRF within the VTA occurred concurrently with SD on days 1 and 10 to assess the CRF response to acute and repeated stress. In Experiment 2, the functional roles of CRF receptors during stress on later cocaine self-administration were assessed through intra-VTA microinjection (uinj) of aCSF, CRF-R1 antagonist, or CRF-R2 antagonist before each social defeat. In Experiment 3, the enduring role of CRF in the VTA on cocaine seeking after forced abstinence in previously stressed animals was assessed through intra-VTA microinjection of aCSF, CRF-R1, or CRF-R2 antagonist before reinstatement ( $\boldsymbol{A}$ ) or microdialysis for CRF in the VTA ( $\boldsymbol{B}$ ).

\section{Experimental design}

The experimental design is shown in Figure 1. Rats underwent intermittent social defeat stress (stressed groups) or handling (control groups) on days 1, 4, 7, and 10. In Experiment 1, rats concurrently underwent in vivo microdialysis for extracellular CRF in the VTA during social defeat on days 1 and 10 to examine the CRF response to acute and repeated social defeat stress or handling.

Experiments 2 and 3 examined the impact of these phasic and tonic VTA CRF responses to repeated social defeat stress on subsequent cocaine taking and seeking behavior. In Experiment 2, the role of CRF receptors in the aVTA vs pVTA during social defeat was investigated. Rats were microinjected with vehicle, a CRF-R1 antagonist, or a CRF-R2 antagonist into the aVTA or pVTA before each social defeat or control handling and subsequently catheterized for intravenous cocaine selfadministration, culminating in a $24 \mathrm{~h}$ binge.

Finally, Experiment 3 evaluated the role of VTA CRF and its receptors long after stress in a translational model of cocaine seeking. Rats underwent intermittent social defeat stress or handling and then underwent cocaine self-administration followed by $15 \mathrm{~d}$ forced abstinence. Rats were returned to the cocaine self-administration chamber and responses were recorded on the lever previously paired with cocaine reinforcement. Upon reintroduction to the cocaine self-administration chamber, vehicle, CRF-R1 antagonist, or CRF-R2 antagonist was microinjected into the aVTA or pVTA (Experiment 3A) or extracellular CRF was measured by in vivo microdialysis (Experiment $3 \mathrm{~B}$ ).

\section{Social defeat stress}

A modified version of a previously described resident-intruder paradigm (Tornatzky and Miczek, 1993; Boyson et al., 2014; Holly et al., 2015) was used for all experiments. Rats in the stressed groups were exposed to 4 brief social defeats separated by $\sim 72 \mathrm{~h}$ (days $1,4,7$, and 10 ). The female co-resident rat was removed before each defeat, which consisted of three phases. The first phase was instigation, in which the experimental animal ("intruder") was placed in a wire mesh enclosure inside the resident's home cage for $10 \mathrm{~min}$, allowing for visual and olfactory instigation, but preventing tactile contact. The second phase was defeat, in which the protective enclosure was removed and the experimental rat was placed in the resident cage until the experimental rat was held in supine for $10 \mathrm{~s}$, was bitten 10 times, or $5 \mathrm{~min}$ had elapsed. For Experiment 1, all defeats were $5 \mathrm{~min}$ in duration to account for microdialysis sampling time. Attack latency and number of bites were recorded and no statistical difference in latency, bites, or defeat duration was observed between experiments or drug treatment groups. The third phase was threat, in which the experimental rat was then returned to the protective cage inside the resident's home cage for an additional $10 \mathrm{~min}$, after which it was returned to its home cage.

\section{Intracranial surgery}

Rats underwent intracranial surgery under ketamine $(100 \mathrm{mg} / \mathrm{kg}$, i.p. $)$ and xylazine $(6 \mathrm{mg} / \mathrm{kg}$, i.p.) anesthesia when indicated below in the detailed methods for each experiment. Rats were and implanted with either a unilateral microdialysis guide cannula (8 mm length; Synaptech) in Experiments 1 and $3 \mathrm{~B}$ or bilateral microinjection cannluae $(23 \mathrm{Ga}, 11$ mm length; PlasticsOne) in Experiments 2 and $3 \mathrm{~A}$ at a $10^{\circ}$ angle 5.0, 5.2, or $5.4 \mathrm{~mm}$ posterior from bregma and $1.8 \mathrm{~mm}$ lateral from the midline at a depth of $7.5 \mathrm{~mm}$ from the skull surface. Rats were allowed to recover for at least 1 week before further manipulation.

\section{Histology}

At the termination of experiments, rats were anesthetized with sodium pentobarbital (100 $\mathrm{mg} / \mathrm{kg}$, i.p.) and transcardially perfused with $0.9 \%$ saline followed by $4 \%$ paraformaldehyde. Brains were removed and placed in $4 \%$ paraformaldehyde for at least $24 \mathrm{~h}$, after which they were sliced into $50 \mu \mathrm{m}$ sections, mounted onto microscope slides, stained with cresyl violet, and coverslipped as described previously (Holly et al., 2012; Holly et al., 2015). Slides were examined under light microscopy for verification of microdialysis probe and microinjection cannula placement. It has been a challenge to define the boundaries of VTA subregions consistently because early characterizations of dopaminergic neurons in the rat VTA (Lindvall and Björklund, 1974; Fallon and Moore, 1978; Swanson, 1982). Although some have defined the aVTA/pVTA more caudally, the emergence of the paranigral nucleus of the VTA beginning around the interpeduncular fossa and nucleus ( $-5.20 \mathrm{~mm}$ from bregma) is a common division in pharmacological, anatomical, and behavioral studies (Ikemoto et al., 1998; Rodd-Henricks et al., 2000; Ikemoto and Wise, 2002; Ikemoto, 2007; Hauser et al., 2014; Sanchez-Catalan et al., 2014; Holly and Miczek, 2016). Therefore, the present studies set the emergence of the interpeduncular fossa and nucleus as the boundary between the aVTA and pVTA.

\section{Experiment 1: Microdialysis during social defeat for CRF in the VTA}

Experiment 1 measured CRF in the VTA during acute and repeated social defeat stress. Rats underwent intracranial surgery, after which they were exposed to intermittent social defeat stress on days $1,4,7$, and 10, with microdialysis performed concurrently on days 1 and 10 . Nonstressed controls underwent microdialysis on days 1 and 10, but were transferred to a clean, empty cage and briefly handled in lieu of social defeat. A timeline for Experiment 1 is shown in Figure $2 A$ and histology is shown in Figure 3.

\section{In vivo microdialysis}

Rats underwent intracranial surgery 1 week before the first microdialysis day. In vivo microdialysis for CRF in the VTA was performed from the same site on both days 1 and 10 of the social defeat protocol as described above. On the night before sample collection, the microdialysis guide cannula was removed and replaced with a microdialysis probe $(2 \mathrm{~mm}$ active polyacrylonitrile membrane, $0.36 \mathrm{~mm}$ OD, $20 \mathrm{kDa}$ cutoff; Synaptech), which was perfused with artificial CSF (aCSF, $147 \mathrm{mmol} / \mathrm{L} \mathrm{NaCl}$, $2.7 \mathrm{mmol} / \mathrm{L} \mathrm{KCl}, 1.2 \mathrm{mmol} / \mathrm{L} \mathrm{CaCl}_{2}, 0.85 \mathrm{mmol} / \mathrm{L} \mathrm{MgCl}_{2}$ ) at a flow rate of $0.5 \mu \mathrm{l} / \mathrm{min}$ overnight. The following morning, the aCSF was replaced 


\section{A}

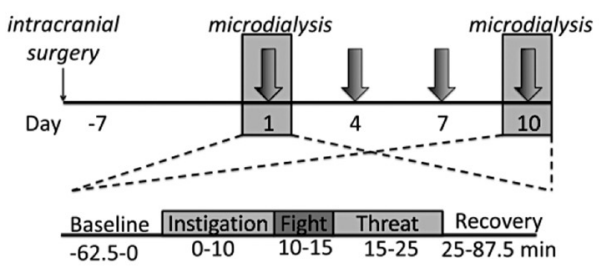

D

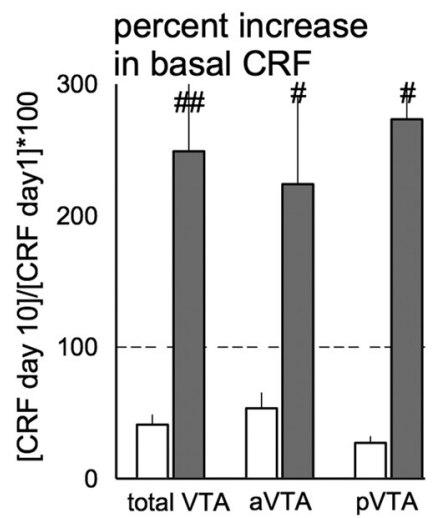

B

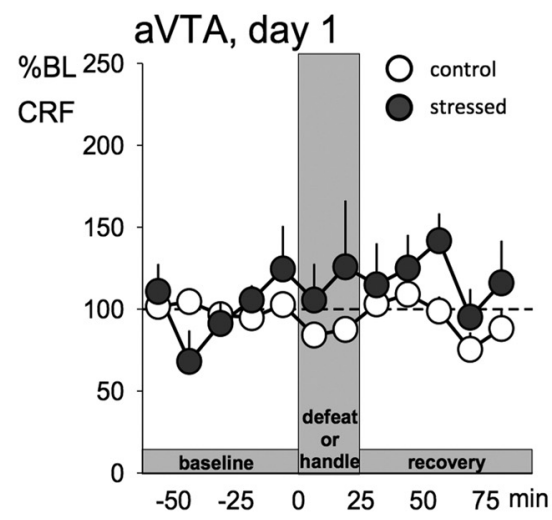

$\mathbf{E}$

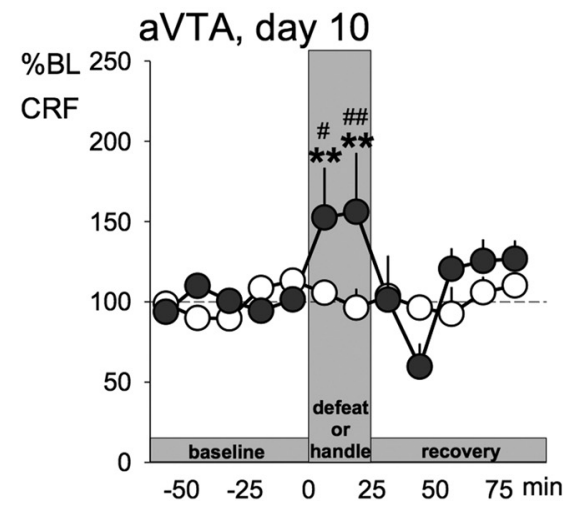

C

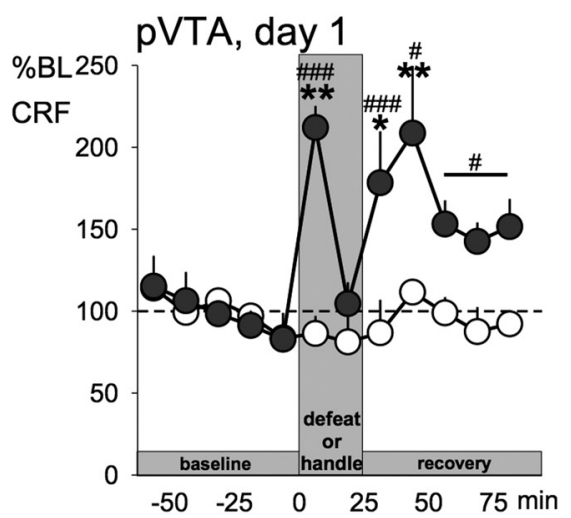

$\mathbf{F}$

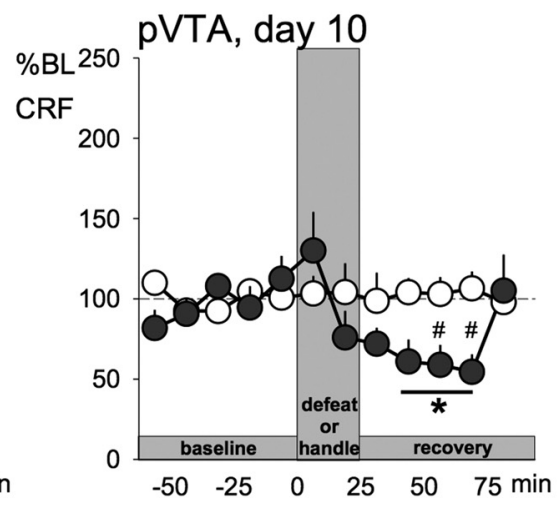

Figure 2. Experiment 1: Microdialysis for CRF in the VTA during acute and repeated social defeat stress. $A$, Experimental timeline. Top, Microdialysis occurred during social defeat stress on days 1 and 10 of the intermittent social defeat protocol, consisting of defeats (arrows) on days 1, 4, 7, and 10. Bottom, During microdialysis, five baseline samples were collected, followed by social defeat stress (instigation, fight, and threat), and an additional five recovery samples were collected after the termination of defeat. $B$, During acute defeat, CRF was not significantly changed from baseline in the aVTA during social defeat stress (gray circles, $n=5$ ) or control handling (white circles, $n=5$ ). C, During acute defeat, (RF was phasically increased in the pVTA both during the initial part of social defeat and in response to stress termination (gray circles, $n=5$ ), but was not changed from baseline during control handling (white circles, $n=5$ ). $\boldsymbol{D}, 0$ n day 10 , compared with nonstressed controls (white bars, $n=5$ in aVTA, $n=5$ in pVTA), stressed rats (gray bars, $n=5$ in aVTA, $n=6$ in pVTA) exhibited significantly greater tonic baseline levels of (RF in the VTA, measured in the five baseline samples before defeat stress, expressed as a percentage of average baseline CRF concentration on day 1 compared with day $10 . E$, On day 10, CRF was increased in the aVTA during the last social defeat episode (gray circles, $n=5$ ), whereas it remained unchanged during control handling (white circles, $n=5$ ). $\boldsymbol{F}$, Within the pVTA, CRF is suppressed during the final social defeat (black circles, $n=6$ ), but unchanged during control handling (white circles, $n=5$ ). ${ }^{*} p<0.05,{ }^{* *} p<0.01$ versus baseline. \#p $<0.05$, \#\#p $<0.01$, \#\#\# $<0.001$ versus nonstressed controls.

with aCSF containing $0.2 \%$ bovine serum albumin (BSA) and the flow rate increased to $2.0 \mu \mathrm{l} / \mathrm{min} 2 \mathrm{~h}$ before sample collection. Samples were collected by hand into Eppendorf Protein LoBind tubes every $12.5 \mathrm{~min}$ and immediately stored at $-80^{\circ} \mathrm{C}$. Tonic levels of CRF were measured in five baseline samples before experimental manipulations. Experimental rats were then transferred to a resident rat's home cage for social defeat as described above, with samples collected ongoing throughout defeat. After the rat was removed from the threat phase, five additional samples were collected to evaluate the time course of CRF changes during "recovery." On days 4 and 7 , social defeats occurred in an identical manner without microdialysis. Nonstressed controls underwent a similar procedure, but were placed in a clean, empty cage for the 10 min instigation and threat periods and briefly handled in lieu of social defeat.

\section{Microdialysis probe recovery}

Recovery of microdialysis probes was determined in vitro at the end of the experiment. After removal from the rat brain at the end of the experiment, probes were immersed in a vial containing $0.5255 \mathrm{~nm}$ CRF and aCSF $+0.2 \%$ BSA perfused at a flow rate of $2.0 \mu \mathrm{l} / \mathrm{min}$. After at least 30 min, 12.5 min samples were collected into $0.5 \mathrm{ml}$ Eppendorf Protein LoBind tubes and both the recovery sample and standard were stored in the $-80^{\circ} \mathrm{C}$ freezer until CRF concentration was determined by enzyme immunoassay (EIA). Mean probe recovery was $12.6 \%$.

\section{CRF EIA}

CRF from dialysate or recovery samples was measured by a commercially available EIA kit (S-1169.0001; Peninsula Laboratories). Some steps of the provided protocol were adjusted to optimize detection. Standards were diluted with aCSF $+0.2 \%$ BSA rather than the provided standard diluent buffer, such that standards and samples were treated equally. Either $25 \mu \mathrm{l}$ (Experiment 1) or $20 \mu \mathrm{l}$ (Experiment 3B) standards or samples were pipetted into each well, as opposed to the recommended 50 $\mu \mathrm{l}$, but all other reagent volumes were identical to the recommended protocol. After the addition of TMB solution, the developing color was read approximately every $5 \mathrm{~min}$ at $630 \mathrm{~nm}$, and the reaction terminated using $2 \mathrm{~N} \mathrm{HCl}$ and absorbance reread at $450 \mathrm{~nm}$. Initial pilot experiments determined that $\sim 15-20 \mathrm{~min}$ (as opposed to the recommended 30-60 min) was the optimal time to terminate the TMB reaction. All other incubation times were identical to the recommended EIA protocol.

All samples were greater than the limit of detection (LoD) and within the linear range of the standard curve, near the half-maximal inhibitory concentration $\left(\mathrm{IC}_{50}\right)$. The LoD was $0.0046 \mathrm{nM}$, calculated according to the Clinical and Laboratory Standards Institute published guideline EP17, Protocols for Determination of Limits of Detection and Limits of Quantitation (Clinical and Laboratory Standards Institute, 2004). The interplate coefficient of variance $(\% \mathrm{CV})$ of the standard concentration 


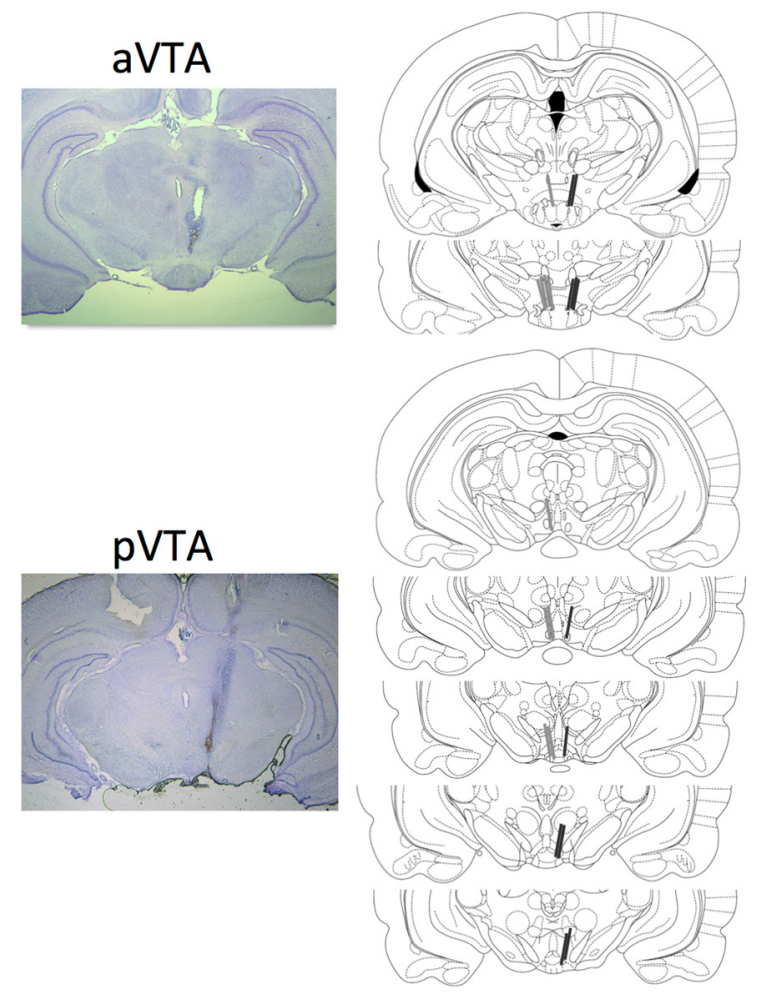

Figure 3. Histology for Experiment 1. Representative photopictomicrographs of probe placement in the aVTA and pVTA are shown on the left, with schematics on the right depicting all probe placements of control (shown on left side of brain, aVTA $n=5, \operatorname{pVTA} n=5$ ) and stressed (aVTA $n=5, \operatorname{pVTA} n=6$ ) rats.

closest to actual values obtained $(0.525 \mathrm{~nm})$ was $5.571 \%$ and the mean intraplate \%CV was $1.386 \%$ (range: $0.367-3.479 \%$ ).

\section{Experiment 2: Role of VTA CRF during stress on later cocaine taking}

Experiment 2 evaluated whether intra-VTA antagonism of CRF receptors during social stress prevents later escalated cocaine selfadministration. To meet this objective, rats were microinjected with vehicle (aCSF), a CRF-R1 antagonist (CP376395, $500 \mathrm{ng} / \mathrm{side}$ ), or CRF-R2 antagonist (Astressin2B, $1000 \mathrm{ng} /$ side) into the aVTA or pVTA 10 min before the instigation phase of each defeat or handling for nondefeated controls. The doses of each drug were chosen based on previous in vivo work (Henry et al., 2006; Blacktop et al., 2011; Boyson et al., 2014). Rats were then catheterized for subsequent intravenous cocaine selfadministration and ultimately exposed to a $24 \mathrm{~h}$ binge (for timeline, see Fig. 4A). Histology is shown in Figure 5.

\section{Microinjections and social defeat stress}

Rats underwent intracranial surgery 1 week before the first microinjection. Microinjections occurred before social defeat or brief handling for nondefeated controls on days 1, 4, 7, and 10. Drugs were microinjected into the VTA with an infusion pump (CMA 102; CMA Microdialysis) using $33 \mathrm{Ga}$ microinjectors protruding $1 \mathrm{~mm}$ beyond the guide cannulae (PlasticsOne). All drugs and vehicle were administered in a volume of $0.25 \mu \mathrm{l} /$ side for $1 \mathrm{~min}$. Injectors were left in place for an additional $1 \mathrm{~min}$ to allow for diffusion from injection site and prevent backflow. Social defeat, as described above, began $10 \mathrm{~min}$ after the beginning of the microinjection. Nonstressed control rats were briefly handled in lieu of defeat stress.

\section{Intravenous catheterization}

Rats were catheterized for cocaine self-administration 11-12 d after the last social defeat episode. Rats were implanted with a catheter (SILASTIC silicon tubing, inner diameter $0.63 \mathrm{~mm}$, outer diameter $1.17 \mathrm{~mm}$; Dow-
Corning) in the right jugular vein under ketamine $(100 \mathrm{mg} / \mathrm{kg}$, i.p. $)$ and xylazine $(6 \mathrm{mg} / \mathrm{kg})$ anesthesia as described previously (Holly et al., 2012; Boyson et al., 2014). The catheter was passed subcutaneously over the shoulder and exited from a small incision between the scapulae, where it was affixed to a pedestal mounted inside a harness (SAI Infusion Technologies). Rats were allowed to recover for at least $5 \mathrm{~d}$ and were then moved from their home cage to permanent housing in cocaine selfadministration chambers. Rats were housed in custom-built acrylic cages $(30 \times 20.5 \times 24.5 \mathrm{~cm})$ lined with Cellu-Dri pellet bedding (Shepherd Specialty Papers). The cage had a removable panel on one wall, which was replaced with a custom-built panel containing one cue light, one session light, and two retractable levers. The cages and panels were contained in larger sound-attenuating chambers. To ensure catheter patency, catheters were flushed daily with $0.2 \mathrm{ml}$ of saline and $0.2 \mathrm{ml}$ of heparinized saline $(20 \mathrm{IU} / \mathrm{ml}) ; 0.17 \mathrm{ml}$ pulses of saline were delivered every $30 \mathrm{~min}$ when self-administration sessions were not running. If patency was questioned, propofol $(10 \mathrm{mg} / \mathrm{ml})$ was infused to test the catheter.

\section{Cocaine self-administration}

Rats were allowed to self-administer cocaine $(0.75 \mathrm{mg} / \mathrm{kg} /$ infusion $)$ freely without priming or autoshaping during daily self-administration sessions that began $\sim 2 \mathrm{~h}$ into the dark cycle. Sessions were signaled by a stimulus light and two retractable levers were extended from one wall of the home cage. Pressing the active lever resulted in a cocaine infusion paired with a cue light. Cocaine infusions were followed by a $30 \mathrm{~s}$ timeout period, during which stimulus and cue lights were off and lever presses were recorded, but had no effect. Throughout the session, pressing the inactive lever was recorded, but was neither reinforced nor punished.

Acquisition/maintenance. Rats were initially trained on a fixed ratio 1 (FR1) schedule of reinforcement, in which each lever press resulted in an intravenous infusion of cocaine. After 2 consecutive days of 15 infusions at FR1, the schedule was gradually increased to FR5. If rats did not meet acquisition criteria within the first $2 \mathrm{~d}$ of cocaine self-administration, they were behaviorally shaped with female urine or Fruit Loops on the active lever. Due to behavioral shaping, group differences in acquisition performance could not be assessed. Daily FR sessions were terminated after 15 infusions or $5 \mathrm{~h}$. Rats were maintained on the FR5 schedule of reinforcement for $5 \mathrm{~d}$ to ensure stable and consistent responding across all stress and drug treatment groups.

Progressive ratio. Sessions then alternated between FR5 maintenance sessions and progressive ratio (PR) sessions for $6 \mathrm{~d}$ ( $3 \mathrm{~d}$ each). During PR sessions, rats were required to respond with an increasing number of lever presses to achieve an infusion of cocaine $(0.3 \mathrm{mg} / \mathrm{kg} /$ infusion $)$. The PR schedule of reinforcement, adapted from Richardson and Roberts (1996), was 1, 2, 4, 6, 9, 12, 15, 20, 25, 32, 40, 50, 62, 77, 95, 118, 145, 178. Sessions ended after $60 \mathrm{~min}$ without cocaine infusion.

$24 \mathrm{~h}$ binge. After the last PR session, rats were given 1 more FR5 maintenance day and, the following day, were given unlimited access to cocaine $(0.3 \mathrm{mg} / \mathrm{kg} /$ infusion $)$ on an FR5 schedule for $24 \mathrm{~h}$. After completion of the binge, catheter patency was tested by propofol injection. Data presented here are a reanalysis of previously published data (Boyson et al., 2014) because the prior publication did not assess or account for probe placement location within the VTA.

\section{Experiment 3: Role of VTA CRF after stress on cocaine seeking after abstinence}

Experiment 3 investigated whether the effects of repeated stress on VTA $\mathrm{CRF}$ and its receptors persist long after social defeat and affect later cocaine seeking after forced abstinence, which has been proposed as a translational model of relapse (Reichel and Bevins, 2009). Compared with nonstressed control rats, we demonstrate that previously stressed rats show greater lever pressing after forced abstinence.

Experiment 3A first evaluates whether the increased cocaine seeking in previously stressed rats can be blocked by CRF-R antagonism in the aVTA or pVTA. One possible explanation for intra-VTA CRF-R antagonism preventing cocaine seeking after forced abstinence in previously stressed rats is that the reintroduction to the context previously associated with cocaine stimulates a greater phasic CRF increase in the VTA of previously stressed rats compared with nonstressed controls. To test this hypothesis, a separate co- 

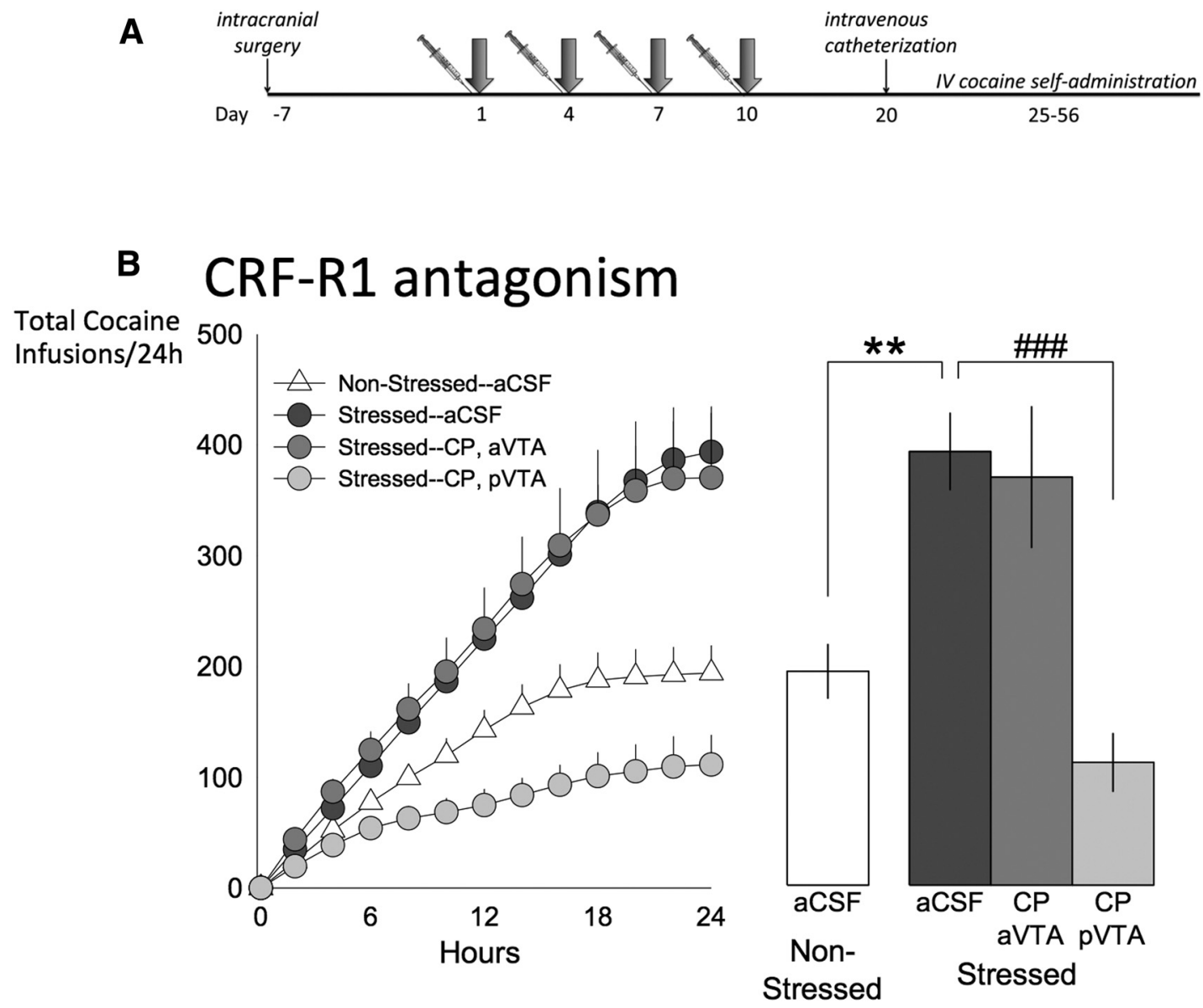

\section{CRF-R2 antagonism}

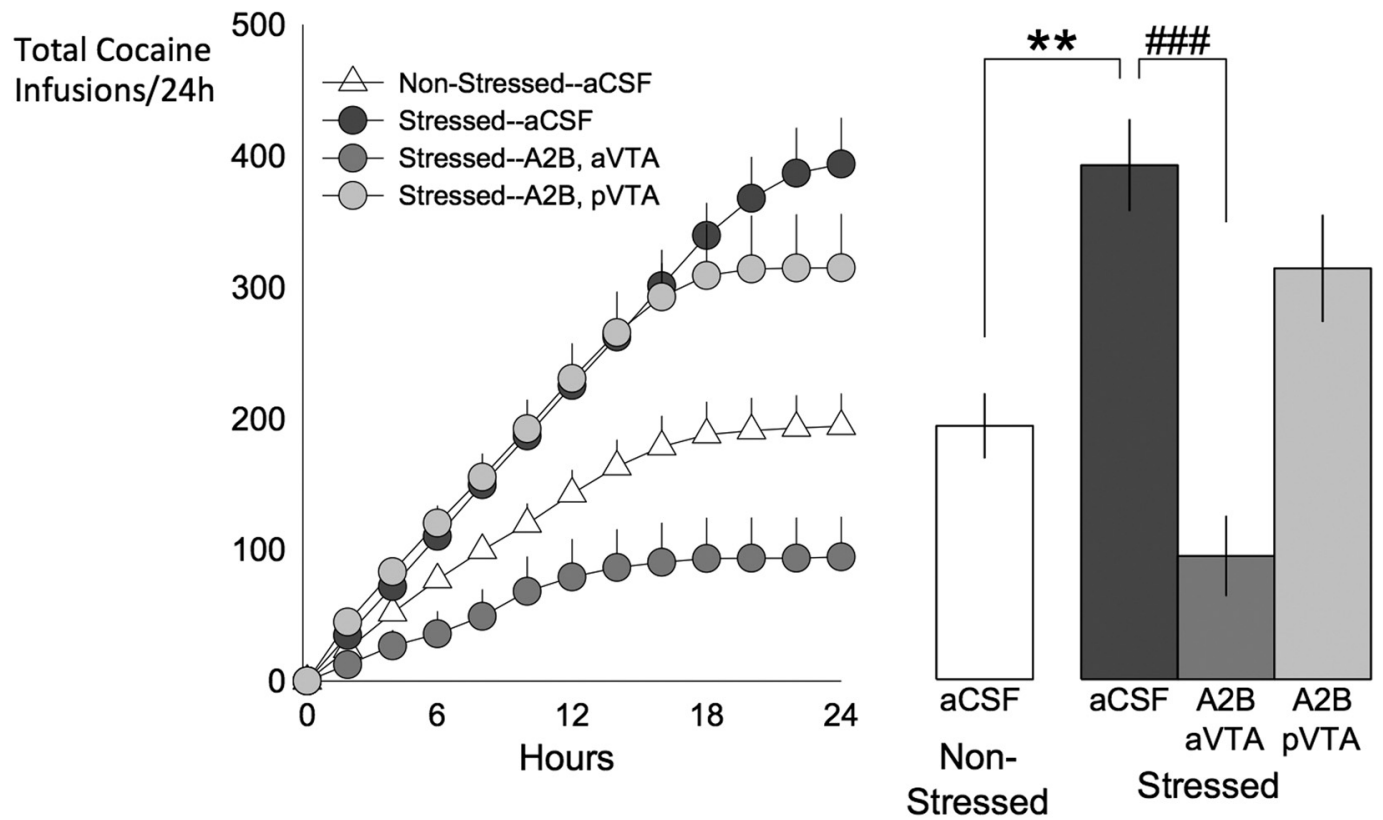

Figure 4. Experiment 2: Role of VTA CRF during stress on later cocaine self-administration. A, Experimental timeline. Vehicle (aCSF), CRF-R1 antagonist (CP376395, CP), or CRF-R2 antagonist (Astressin2B, A2B), was microinjected into the VTA before each social defeat (arrows), after which animals were catheterized for intravenous cocaine self-administration, culminating in a $24 \mathrm{~h}$ binge. $\boldsymbol{B}$, Stressed rats pretreated with aCSF before each social defeat (dark gray, $n=11$ ) self-administered significantly more cocaine during the $24 \mathrm{~h}$ binge compared with aCSF-pretreated nonstressed controls (white, $n=13$ ). This was prevented with intra-pVTA antagonism of CRF-R1 (light gray, $C P, n=4$ ), but not intra-aVTA CRF-R1 antagonism (medium gray, CP, $n=4$ ). Cumulative infusions in $2 \mathrm{~h}$ bins are shown on the left, with total infusions shown on the right. C, Conversely, intra-aVTA CRF-R2 antagonism (medium gray, A2B, $n=4$ ), but not intra-pVTA CRF-R2 antagonism (light gray, $\mathrm{A} 2 \mathrm{~B}, n=5$ ), prevented stress-escalated cocaine self-administration during the $24 \mathrm{~h}$ binge. Complete data with all control groups are shown in Table $3 .{ }^{* *} p<0.01$ versus aCSF-nonstressed, \#\#\#p $<$ 0.001 versus aCSF-stressed. 


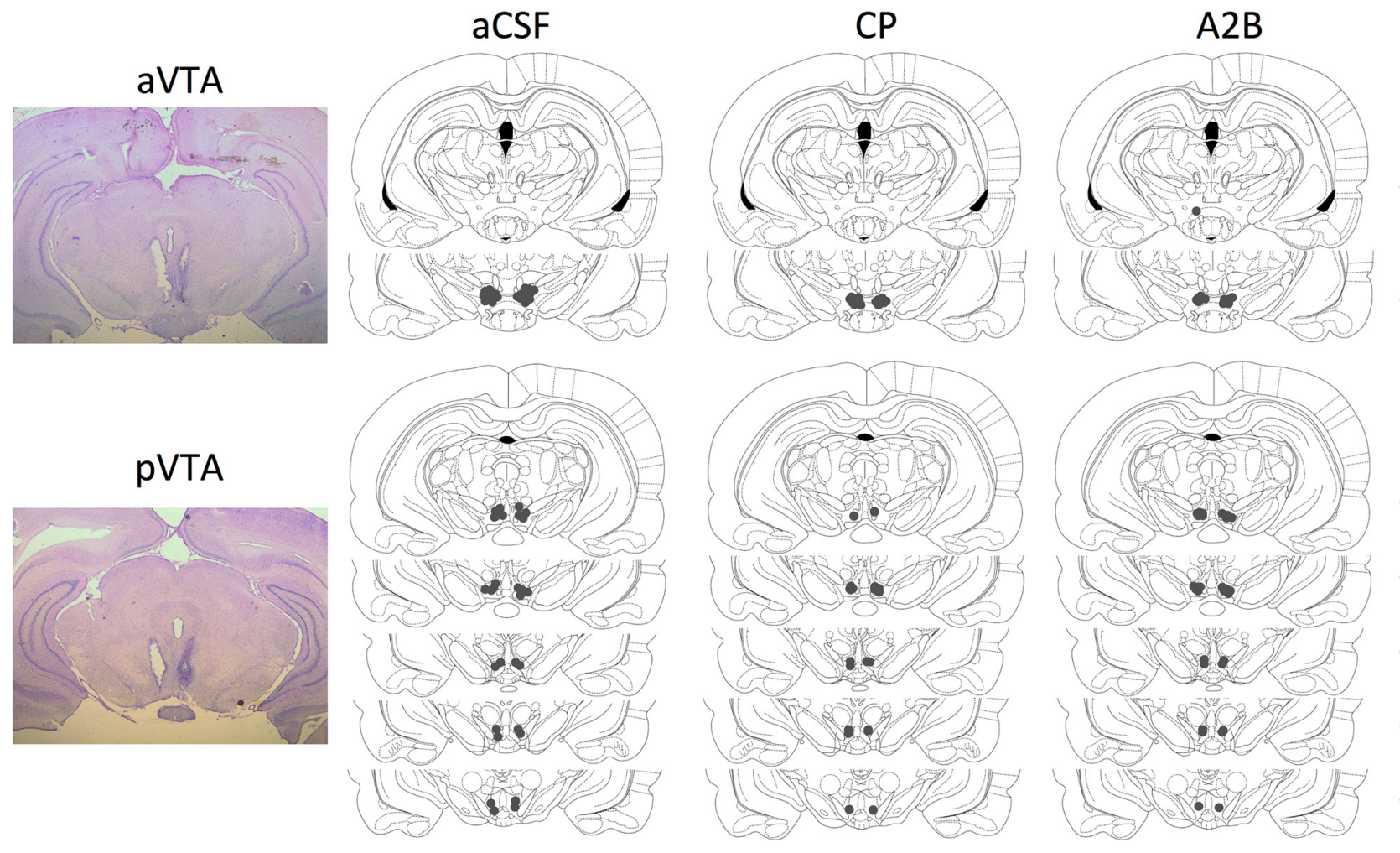

Figure 5. Histology for Experiment 2. Representative photopictomicrographs of microinjection cannula placement in the aVTA and pVTA are shown on the left, with schematics on the right depicting spread of all placements for animals pretreated with aCSF ( $\mathrm{VVTA} n=10, \mathrm{pVTA} n=14),(\mathrm{P} 376395(\mathrm{CP}, \mathrm{aVTA} n=9, \mathrm{pVTA} n=9)$, and Astressin2B (A2B, aVTA $n=8, \mathrm{pVTA} n=14)$.

hort of rats underwent in vivo microdialysis of CRF in the VTA during reinstatement testing in Experiment 3B. The experimental timeline is shown in Figure $6 A$ and histology is shown in Figure 7.

\section{Cocaine self-administration}

Rats underwent intermittent social defeat stress or brief handling on days $1,4,7$, and 10 , as described above. One to $2 \mathrm{~d}$ after the last social defeat episode (or handling for nonstressed controls), rats underwent intravenous catheterization as described in Experiment 2. After $5 \mathrm{~d}$ of recovery, rats were transferred to sound-attenuating chambers, where they remained until abstinence and then began cocaine self-administration. Daily self-administration sessions were modified slightly from Experiment 2 to be more similar to other reports of cocaine seeking after forced abstinence (Fuchs et al., 2006; See et al., 2007; Hearing et al., 2008). Rats were initially trained on an FR1 schedule of reinforcement for cocaine $(0.75 \mathrm{mg} / \mathrm{kg} /$ infusion $)$ and sessions were terminated after 30 infusions or $3 \mathrm{~h}$. After 2 consecutive days of $>15$ infusions, the schedule of reinforcement was gradually increased to FR3, where rats were maintained until they reached a criterion of 10 consecutive days of $>15$ infusions.

Forced abstinence. After the criterion was met, rats were moved from the self-administration room into a separate vivarium room for $15 \pm 1 \mathrm{~d}$ of forced abstinence. The panel containing the session light, cue light, and retractable levers was removed and replaced with a wire mesh panel and the cages were moved from the sound-attenuating chambers in the self-administration room into a separate vivarium room. The soundattenuating chambers were not cleaned or used during the abstinence period to retain any potential contextual odor cues, but each rat's bedding was changed weekly. Intracranial surgery was performed $\sim 7 \mathrm{~d}$ into the abstinence period.

Cocaine seeking after abstinence. Rats were brought from their temporary housing room to their previous cocaine-self-administration soundattenuating chamber. The wire mesh panel on their cage was replaced with their previous self-administration panel and a $3 \mathrm{~h}$ session began. During this session, the two levers were extended and the stimulus light was illuminated; however, now, pressing the active or inactive lever was recorded but did not result in any reinforcement, previously paired cue light, or timeout period.

\section{Experiment 3A: Intra-VTA antagonism of CRF receptors during} cocaine seeking

Rats were microinjected in their temporary housing room with vehicle (aCSF), CRF-R1 antagonist (CP376395, $500 \mathrm{ng} /$ side), or CRF-R2 antagonist (Astressin2B, $1000 \mathrm{ng} / \mathrm{side}$ ) in the aVTA or pVTA $20 \mathrm{~min}$ before reintroduction to the cocaine self-administration chamber.

Experiment 3B: In vivo microdialysis for CRF in the VTA during cocaine seeking

The night before reintroduction to the cocaine self-administration chamber, a separate group of rats was prepared for in vivo microdialysis in their temporary housing room. Microdialysis was performed and CRF measured by EIA as described in Experiment 1, except samples were collected every $10 \mathrm{~min}$. After 5 baseline samples, rats were quickly brought to their self-administration chamber and samples continued to be collected throughout the $3 \mathrm{~h}$ cocaine-seeking session.

\section{Results}

Experiment 1: Microdialysis during social defeat for CRF in the VTA

Acute stress phasically increases extracellular CRF in the $p V T A$, but not aVTA

Regardless of probe placement within the VTA, baseline nanomolar concentrations of CRF did not vary between groups on day 1 (Table 2). Due to slight variability in nanomolar concentrations across multiple EIA runs and significantly different baseline values on day 10 (described below), data reported here were standardized as the percentage change from the average concentration of the five baseline samples (subsequently referred to as percentage change from baseline). Within both the aVTA and pVTA, there were no effects of stress group or sample or stress 
A

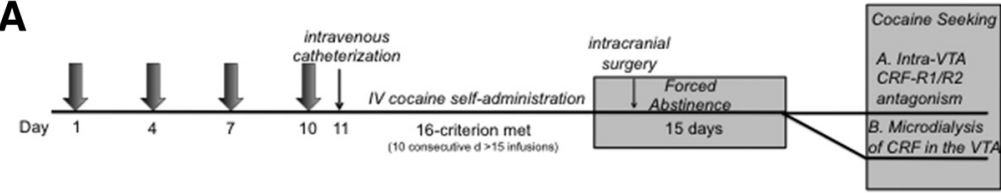

B CRF-R1 antagonism Acquisition

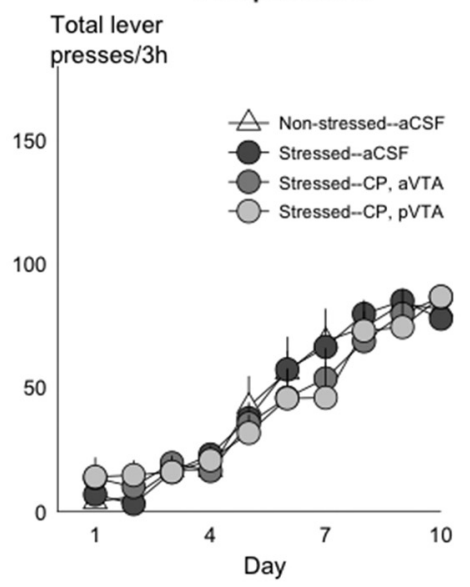

C CRF-R2 antagonism Acquisition

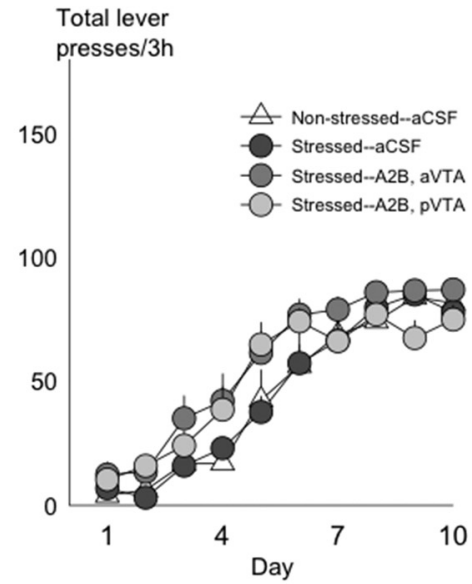

D CRF concentration
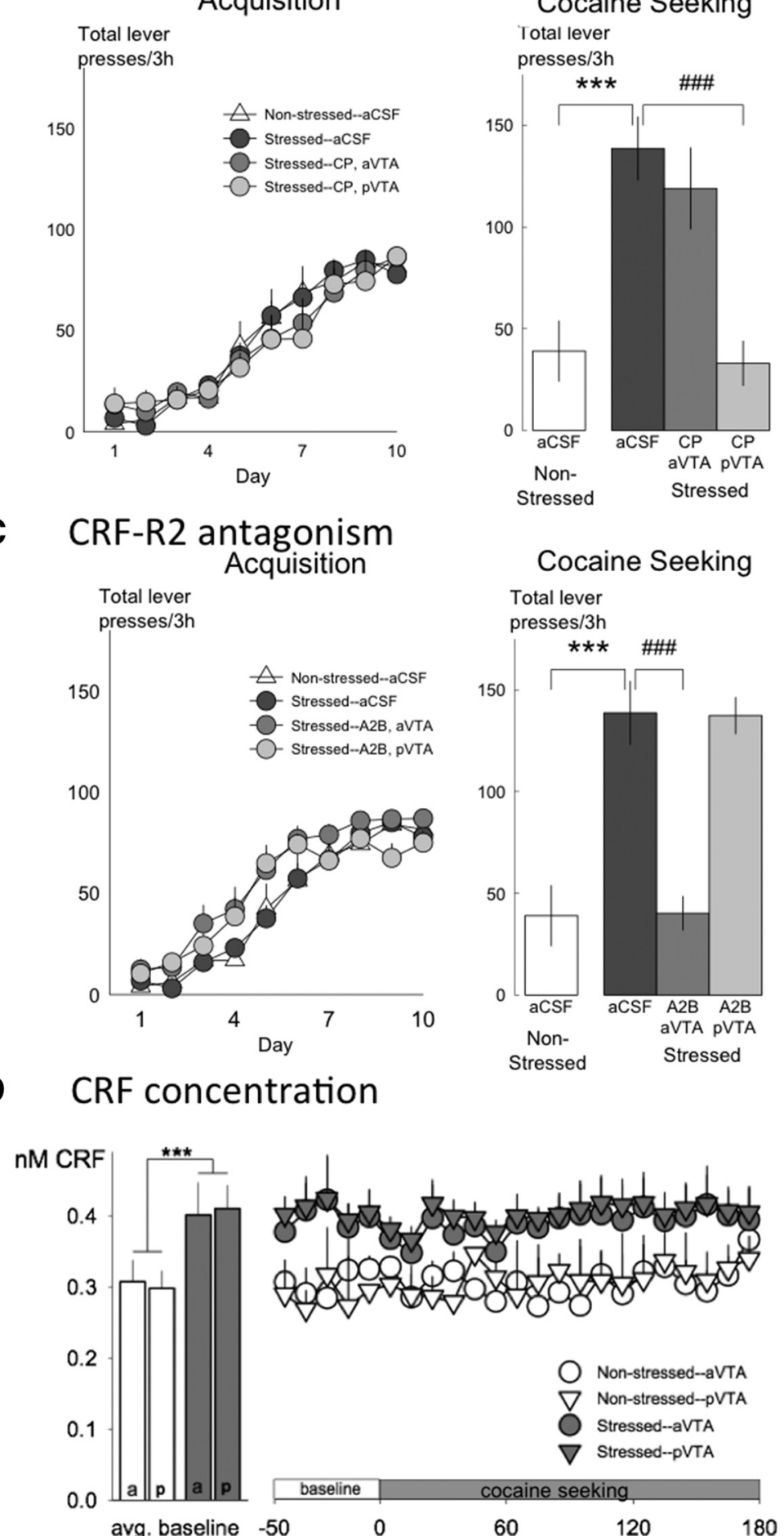

\section{Cocaine Seeking}




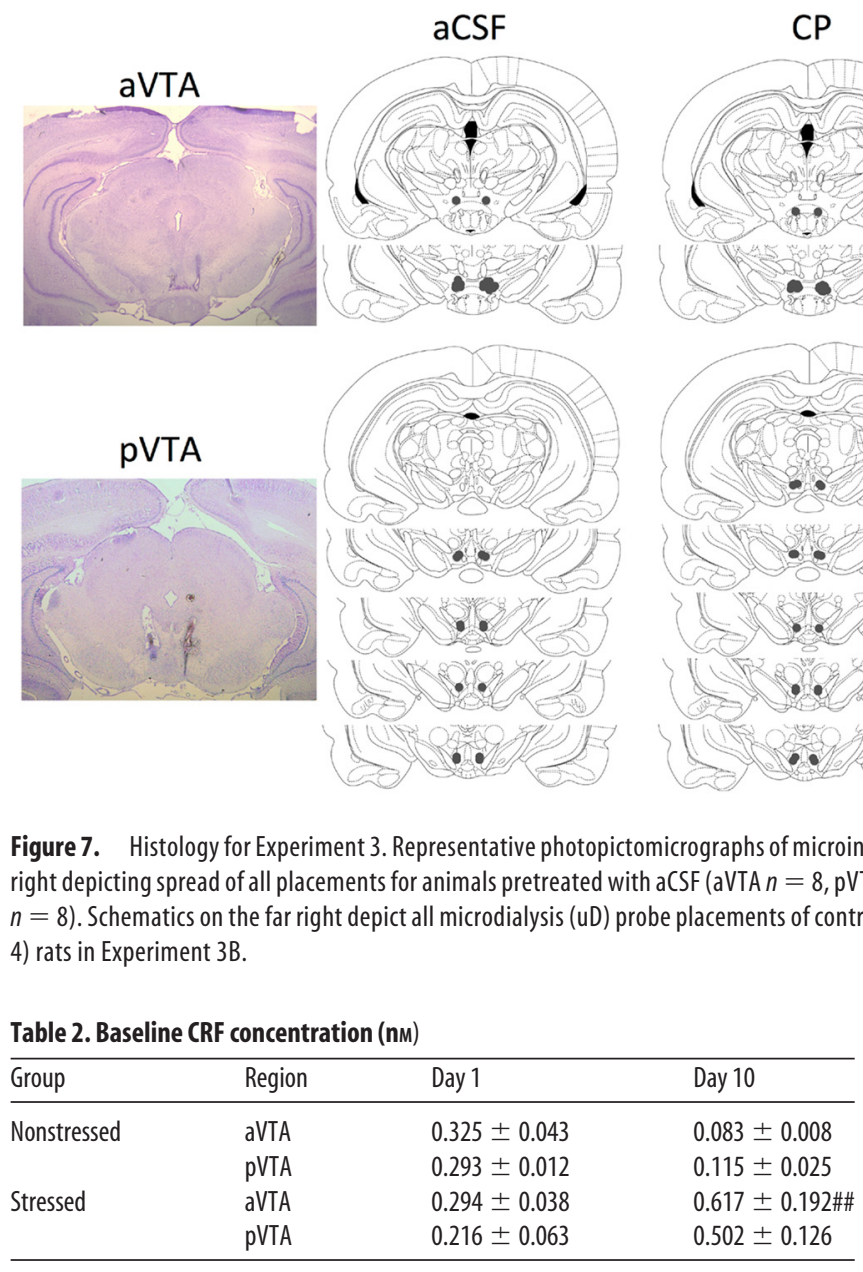

Data are represented as mean \pm SEM.

$\#$ \# $<0.01$ versus day 1.

from baseline within the control group. Furthermore, also probing the interaction, extracellular CRF in the stressed group was significantly greater than in the control group during the first half of social defeat stress (Holm-Sidak $t=4.947, p<0.001$ ), as well as during all samples after social defeat ended (first sample: Holm-Sidak $t=3.601, p<0.001$, second sample: Holm-Sidak $t=$ 3.820, $p<0.001$, third sample: Holm-Sidak $t=2.133, p=0.038$, fourth sample: Holm-Sidak $t=2.166, p=0.035$, fifth sample: Holm-Sidak $t=2.335, p=0.024)$.

Repeated stress increases tonic CRF in the VTA

On the last day of intermittent social defeat stress, tonic levels of CRF were increased in stressed rats regardless of probe placement within the VTA, whereas they were decreased within nonstressed controls (Table 2).

Two-way repeated-measures ANOVA of nanomolar baseline concentrations revealed a significant main effect of stress $\left(F_{(1,15)}=4.906, p=0.043\right)$ and an interaction of stress condition and day $\left(F_{(1,15)}=13.247, p=0.002\right)$, but no main effect of day. Within the stressed group, there was a significant increase in tonic CRF from day 1 to day 10 (Holm-Sidak $t=3.182, p=$ $0.006)$, but with the current sample size, the decrease in tonic CRF observed within nonstressed controls did not reach statistical significance (Holm-Sidak $t=2.083, p=0.055)$. There was, however, a significant effect of stress group on day 10, with tonic CRF levels substantially greater within stressed animals than those of nonstressed controls (Holm-Sidak $t=3.617, p<0.001$ ).
Separate analysis of VTA subregions revealed the same statistical effects and trends. Within the aVTA, there was a significant interaction between stress group and day $\left(F_{(1,7)}=6.825, p=\right.$ $0.035)$ and CRF tone was significantly greater in stressed compared with nonstressed rats on day 10 (Holm-Sidak $t=3.357$, $p=0.005)$. There were no significant effects in the pVTA.

Baseline CRF concentration on day 10 was also analyzed as a percentage increase from the day 1 baseline concentration within each rat. In this manner, the change in CRF concentration from day 1 to day 10 was readily apparent, with stressed rats exhibiting an increase in CRF tone compared with day 1 and a decrease in nonstressed rats (Fig. 2C). Two-way ANOVA revealed a significant main effect of stress $\left(F_{(1,13)}=9.451, p=0.009\right)$ with no effects of VTA subregion or stress $X$ subregion interaction. There was a significant effect of stress group within the pVTA (Holm-Sidak $t=2.424, p=$ $0.031)$, but not aVTA (Holm-Sidak $t=1.905, p=0.079)$.

\section{Repeated stress phasically increases extracellular CRF in the} aVTA, but not $p V T A$

After exposure to repeated stress, extracellular CRF is altered within both the aVTA and pVTA during the last defeat. During the final defeat, CRF is slightly elevated above baseline in both the aVTA and pVTA during the first half of social defeat stress, after which they diverge (Fig. 2E, F).

Within the aVTA, CRF remains elevated, after which it returns to baseline (Fig. 2E). Two-way repeated-measures ANOVA revealed a significant main effect of sample $\left(F_{(7,49)}=3.090, p=\right.$ $0.009)$ and a stress group $\times$ sample interaction $\left(F_{(7,49)}=3.175\right.$, $p=0.008)$, but no main effect of stress. Post hoc Holm-Sidak tests for multiple comparisons on the significant interaction revealed that, within the stressed group, extracellular CRF was significantly increased from baseline during both samples during social defeat stress (first sample: Holm-Sidak $t=3.535, p=0.006$; second sample: Holm-Sidak $t=3.356, p=0.009$ ), but did not differ from baseline after the termination of social defeat stress. In contrast, extracellular CRF did not differ from baseline within the control group. In addition, extracellular CRF was significantly 
Table 3. Effects of intra-VTA CRF-R antagonism during stress on cocaine selfadministration FR performance rate, progressive ratio breakpoint (PRBP), and infusions during a $24 \mathrm{~h}$ "binge"

\begin{tabular}{llllrl}
\hline Group & Drug & Region & \multicolumn{1}{l}{ FR rate } & \multicolumn{1}{l}{ PRBP } & \multicolumn{1}{l}{ Binge } \\
\hline Nonstressed & aCSF & aVTA & $0.59 \pm 0.09$ & $7.49 \pm 1.13$ & $179.99 \pm 44.64$ \\
Nonstressed & aCSF & pVTA & $0.64 \pm 0.08$ & $9.71 \pm 0.56$ & $216.00 \pm 32.80$ \\
Nonstressed & CP & aVTA & $0.85 \pm 0.21$ & $10.67 \pm 2.03$ & $183.33 \pm 85.47$ \\
Nonstressed & CP & PVTA & $0.99 \pm 0.22$ & $10.79 \pm 1.36$ & $252.00 \pm 51.80$ \\
Nonstressed & A2B & aVTA & $0.55 \pm 0.23$ & $9.71 \pm 0.83$ & $233.00 \pm 67.42$ \\
Nonstressed & A2B & pVTA & $0.90 \pm 0.13$ & $11.67 \pm 1.07$ & $228.50 \pm 63.29$ \\
Stressed & aCSF & aVTA & $0.76 \pm 0.22$ & $10.42 \pm 1.32$ & $342.50 \pm 41.19^{* *}$ \\
Stressed & aCSF & pVTA & $0.82 \pm 0.05$ & $10.87 \pm 0.85$ & $423.00 \pm 48.69^{* *}$ \\
Stressed & CP & aVTA & $1.19 \pm 0.15$ & $10.67 \pm 0.68$ & $370.40 \pm 64.36$ \\
Stressed & CP & PVTA & $0.79 \pm 0.12$ & $8.83 \pm 1.06$ & $111.40 \pm 26.72 \# \# \#$ \\
Stressed & A2B & aVTA & $0.73 \pm 0.08$ & $8.38 \pm 1.21$ & $94.50 \pm 30.68 \# \# \#$ \\
Stressed & A2B & PVTA & $0.88 \pm 0.06$ & $11.92 \pm 0.88$ & $314.67 \pm 41.03$ \\
\hline
\end{tabular}

Data are represented as mean \pm SEM.

${ }^{* *} p<0.01$ versus nonstressed aCSF; \#\#\# $<0.001$ versus stressed aCSF within the same subregion.

greater in the stressed compared with control group in both samples during social defeat (first sample: Holm-Sidak $t=2.159, p=$ 0.037; second sample: Holm-Sidak $t=2.749, p=0.009)$.

Conversely, within the pVTA, extracellular CRF was suppressed after the termination of social defeat (Fig. 2F). Two-way repeated-measures ANOVA revealed a significant stress group $\times$ sample interaction $\left(F_{(7,63)}=2.281, p=0.038\right)$, but no main effects of stress group or sample. Testing the significant interaction with Holm-Sidak tests for multiple comparisons, a significant decrease from baseline CRF was observed within the stressed group during the second, third, and fourth samples after social defeat stress ended (second sample: Holm-Sidak $t=2.755, p=$ 0.038 ; third sample: Holm-Sidak $t=2.864, p=0.034$; HolmSidak $t=3.097, p=0.020$ ) and percentage baseline CRF was significantly lower in the stressed group compared with control group during the third and fourth samples after social defeat (third sample: Holm-Sidak $t=2.021, p=0.048$; fourth sample: Holm-Sidak $t=2.382, p=0.021)$.

\section{Experiment 2: Role of VTA CRF during stress on later cocaine taking}

Intra-VTA antagonism of CRF-R1 in the PVTA or CRF-R2 in the aVTA during each defeat prevents later escalated cocaine self-administration

The response rate during fixed ratio sessions and the breakpoint in progressive ratio sessions were not affected by stress or pretreatment with CRF receptor antagonists into either VTA subregion before each stress or handling episode (Table 3).

However, stress significantly increased cocaine self-administration during the $24 \mathrm{~h}$ binge and this effect could be prevented with CRF-R1 antagonism in the pVTA or CRF-R2 antagonism in the aVTA (Fig. 5B,C, Table 3). Three-way ANOVA revealed significant interactions of stress group $\times$ drug pretreatment $\left(F_{(2,51)}=6.366, p=0.003\right)$, VTA subregion $\times$ drug pretreatment $\left(F_{(2,51)}=3.167, p=0.05\right)$, and stress group $\times \mathrm{VTA}$ subregion $\times$ drug pretreatment $\left(F_{(2,51)}=10.279, p<0.001\right)$.

Because there was a significant three-way interaction, main effects and two-way interactions cannot be interpreted. The effect of one or more factor is not consistent at all combinations of the other two factors such that an unambiguous interpretation of main effects and two-way interactions is not possible. To interpret the three-way interaction, further two-way post hoc analyses were performed evaluating two-way interactions across one level of the third factor. First, the effects of stress group and VTA subregion were tested within the vehicle-pretreated animals. Within the vehicle group, previously stressed rats selfadministered significantly more cocaine during the $24 \mathrm{~h}$ binge compared with nonstressed controls regardless of VTA subregion (Holm-Sidak $t=2.898, p=0.006)$.

Because there was a significant effect of stress within the vehicle-pretreated animals, we next analyzed the effects of drug pretreatment and VTA subregion within the stressed group. Two-way ANOVA revealed a significant effect of drug pretreatment $\left(F_{(2,28)}=8.521, p=0.001\right)$ and drug pretreatment $\times$ VTA subregion interaction $\left(F_{(2,28)}=18.581, p<0.001\right)$ within the previously stressed rats. Although the number of binge infusions was significantly less in stressed rats pretreated with the CRF-R1 antagonist (Holm-Sidak $t=3.181, p=0.007$ ) and the CRF-R2 antagonist (Holm-Sidak $t=3.902, p=0.002$ ) compared with vehicle-pretreated stressed animals, this was driven by a significant effect of where the antagonists were microinjected. Within stressed rats, CRF-R1 antagonism within the pVTA significantly prevented increased cocaine taking compared with vehicle pretreatment in the pVTA (Holm-Sidak $t=5.316, p<0.001$ ), as well as CRF-R1 antagonism within the aVTA (Holm-Sidak $t=$ 4.091, $p<0.001$ ). In addition, stressed rats pretreated with CRF-R1 antagonist in the pVTA self-administered significantly less than pVTA CRF-R1-pretreated nonstressed controls (HolmSidak $t=4.840, p<0.05)$, which may be a result of antagonism of a phasic rather than tonic CRF response to social stress. Conversely, CRF-R2 antagonism within the aVTA of stressed rats significantly prevented increased cocaine taking compared with vehicle pretreatment in the aVTA (Holm-Sidak $t=3.778, p=$ 0.002 ) and CRF-R2 antagonism within the pVTA (Holm-Sidak $t=4.502, p<0.001)$.

\section{Experiment 3: Role of CRF in the VTA after stress on cocaine seeking after abstinence}

Rats with a history of repeated stress exhibit greater cocaine seeking after forced abstinence compared with nonstressed controls All rats acquired and reliably self-administered cocaine at an FR3 schedule of reinforcement and there was no effect of prior stress history on the number of infusions in daily cocaine self-administration sessions (Fig. 6B, $C$, left). Two-way repeatedmeasures ANOVA revealed a main effect of self-administration day $\left(F_{(9,459)}=177.259, p<0.001\right)$, but no effect of stress group or stress group $\times$ self-administration day interaction. There was also no significant difference between groups on cumulative cocaine earned before forced abstinence (data not shown).

Previously stressed rats microinjected with vehicle demonstrated augmented cocaine seeking after forced abstinence, which was prevented in previously stressed rats treated with antagonists of CRF-R1 in the pVTA (Fig. 6B, right, Table 4) and CRF-R2 in the aVTA (Fig. $6 C$, right, Table 4) before the return to the cocaine self-administration chamber. Three-way ANOVA revealed a significant interaction of VTA subregion $\times \operatorname{drug}\left(F_{(2,38)}=6.479\right.$, $p=0.004)$, as well as stress group $\times \operatorname{drug}\left(F_{(2,38)}=5.910, p=\right.$ $0.006)$, meaning that the effect each CRF receptor antagonist or vehicle in the VTA is dependent on both which VTA subregion it is delivered in and whether the animals were previously stressed. Post hoc Holm-Sidak tests for multiple comparisons were then run to interpret these significant interactions.

Previous intermittent social defeat stress resulted in significantly more lever pressing upon return to the cocaine selfadministration chamber compared with nonstressed controls (Fig. 6B, C, right, Table 4). Previously stressed rats microinjected with aCSF pressed the lever previously associated with cocaine 
Table 4. Effects of intra-VTA CRF-R antagonism during cocaine seeking after forced abstinence in previously stressed or nonstressed rats

\begin{tabular}{lllc}
\hline Group & Drug & Region & Lever presses \\
\hline Nonstressed & aCSF & aVTA & $30.00 \pm 17.01$ \\
Nonstressed & aCSF & pVTA & $66.67 \pm 17.80$ \\
Nonstressed & CP & aVTA & $62.83 \pm 20.30$ \\
Nonstressed & CP & pVTA & $59.25 \pm 26.88$ \\
Nonstressed & A2B & aVTA & $66.86 \pm 24.81$ \\
Nonstressed & A2B & pVTA & $59.67 \pm 11.17$ \\
Stressed & aCSF & aVTA & $134.40 \pm 13.79^{* * *}$ \\
Stressed & aCSF & pVTA & $144.00 \pm 33.71^{* * *}$ \\
Stressed & CP & aVTA & $119.00 \pm 20.10$ \\
Stressed & CP & pVTA & $33.00 \pm 11.14 \# \#$ \\
Stressed & A2B & aVTA & $40.20 \pm 8.42 \# \#$ \\
Stressed & A2B & pVTA & $137.33 \pm 9.12$ \\
\hline
\end{tabular}

Data are represented as mean \pm SEM.

${ }^{* * *} p<0.001$ versus nonstressed aCSF; \#\# $<0.01$ versus stressed aCSF within the same subregion.

significantly more than their last day of cocaine self-administration (one-way repeated-measures ANOVA $F_{(1,17)}=$ $10.549, p=0.012$ ), an effect not seen in aCSF-treated rats with no stress history. The stressed aCSF group also exhibited significantly more cocaine seeking compared with the nonstressed aCSF group (Holm-Sidak $t=3.879, p<0.001)$.

Heightened cocaine seeking in previously stressed rats is associated with increased tonic CRF in the VTA acting on pVTA CRF-R1 and aVTA CRF-R2

The cocaine seeking observed in the stressed group was prevented by antagonism of CRF-R1 in the pVTA and CRF-R2 in the aVTA (Fig. 6B, $C$, right, Table 4). Within the pVTA, responses on the lever previously associated with cocaine reinforcement were significantly reduced in animals treated with CRF-R1 antagonist compared with those treated with aCSF (Holm-Sidak $t=3.274$, $p=0.011$ ), but no difference between CRF-R2 antagonist- and aCSF-treated rats was observed. Conversely, within the aVTA, CRF-R2 antagonism resulted in significantly fewer lever presses compared with aCSF-treated rats (Holm-Sidak $t=3.092, p=$ $0.016)$, with no difference between stressed rats administered aCSF and CRF-R1 antagonist.

Unexpectedly, there was no phasic increase from baseline in extracellular CRF in the VTA during cocaine seeking in either the previously stressed or the nonstressed group (Fig. 6D). However, nanomolar concentrations of CRF were significantly greater in previously stressed compared with nonstressed rats (one-way ANOVA $\left.F_{(1,11)}=6.529, p=0.027\right)$. There was no difference between VTA subregion in either group.

\section{Discussion}

The current experiments suggest dynamic, shifting roles of CRF and its receptors within VTA subregions during and after stress, promoting later escalated cocaine taking and seeking. Acute stress promotes a phasic increase in CRF within the pVTA, whereas repeated stress recruits a phasic CRF response in the aVTA and elevates CRF tone throughout the VTA. CRF acts on CRF-R1 in the pVTA and CRF-R2 in the aVTA during repeated social defeat stress to cause increased cocaine self-administration during a $24 \mathrm{~h}$ binge. Finally, changes in VTA CRF are persistent after stress exposure such that CRF tone remains elevated and may contribute to cocaine seeking after forced abstinence in previously stressed animals through amplified actions on pVTA CRF-R1 and aVTA CRF-R2.

Only one other study reports phasic extracellular CRF changes in the VTA during stress. Wang et al. (2005) demonstrated that acute foot shock stress increases CRF within the VTA. Consistent with this prior work, the current study found increased extracellular CRF in the pVTA during acute stress. Although Wang et al. (2005) did not differentiate between the aVTA and pVTA, our results suggest that CRF efflux differs between these VTA subregions during acute stress.

The time course of phasic CRF fluctuations within the pVTA during acute defeat resemble the pattern of dopaminergic increases in the medial prefrontal cortex (mPFC) and nucleus accumbens shell (NAcSh) (Holly et al., 2015). Here, we show that, after a burst in CRF at the initiation of social defeat, extracellular CRF returns to baseline for the second half of social defeat. Although this return to baseline is difficult to interpret, the variability of this data point is low. Moreover, the pVTA CRF changes during acute defeat parallel our report demonstrating that extracellular MPFC and NAcSh dopamine concentrations are highest in the first half of social defeat stress, but not significantly different from baseline during the final threat period (Holly et al., 2015). Unlike our observations of extracellular dopamine, however, the present data indicate that CRF is again elevated at the termination of defeat, possibly signaling negative reinforcement.

VTA dopamine neurons responsive to acute foot shock are primarily localized in the pVTA (Brischoux et al., 2009). The present observations of phasic CRF increase in the pVTA during acute social defeat stress may be one mechanism underlying stress-induced dopamine neuron activation because CRF bath application increases VTA dopamine neuron firing rate (Korotkova et al., 2006; Wanat et al., 2008) and blockade of VTA CRF-R2 can prevent acute social-stress-induced dopamine efflux in the NAcSh (Holly et al., 2015).

Future work should identify sources of CRF into the aVTA and pVTA and determine which neural circuit(s) is responsible for the observed increase in pVTA CRF during acute stress. However, neuropeptides are not solely released from axon terminals, but may be released from the entire surface of the neuron (Pow and Morris, 1989). Grieder et al. (2014) described CRFcontaining dopaminergic cell bodies within the pVTA, and their activation may be a source of the efflux in extracellular CRF in the pVTA during acute stress. Therefore, although microdialysis captures increased extracellular neuropeptide concentration, the source of the increase cannot be determined conclusively even if distinct inputs are uncovered (Wotjak et al., 2008).

Repeated, as opposed to acute, social stress has been associated with increased psychostimulant self-administration, so the shifts in CRF activity within the VTA with repeated stress are of particular interest. With repeated social defeat, tonic extracellular CRF was significantly increased by $\sim 200 \%$ within stressed animals (Fig. 2D). This increased tone could be due to the recruitment of previously silent CRF neurons (George et al., 2012); increased vesicular storage or increased firing rate of CRF neurons located in, projecting to, or passing through the VTA (van den Pol, 2012); or increased CRF production and somatodendritic release from CRF neurons within the VTA itself (Grieder et al., 2014). However, although CRF remains elevated $>1$ month after social defeat stress ends (Fig. 6D) and we recently demonstrated no change in mesocorticolimbic dopamine tone with repeated defeat (Holly et al., 2015), a conditioned response to anticipation of defeat may contribute to the elevated CRF tone.

Phasic CRF responses are also altered with repeated stress. CRF was not significantly altered in the aVTA during the first defeat, but CRF was significantly increased in the aVTA during the last defeat. This may also reflect the recruitment of previously silent neurons or neuroadaptations resulting in a phasic response 
of already active CRF neurons that do not respond to acute stress. In addition, there was a shift in the phasic response of CRF within the pVTA; after the last defeat CRF is significantly depressed below baseline. Neuropeptides are slower to regenerate within vesicular stores than canonical neurotransmitters (van den Pol, 2012), so this suppression may represent complete depletion of vesicular stores at the beginning of social defeat. However, evoked CRF release during repeated stress may be altered by prior probe implantation.

Phasic CRF responses within the VTA during social defeat stress have important functional consequences on later cocaine self-administration behavior. Intra-VTA CRF-R1 and CRF-R2 antagonism during social defeat prevents the induction of crosssensitization to cocaine and escalated cocaine self-administration during a $24 \mathrm{~h}$ binge (Boyson et al., 2014). No effects on PR breakpoints were observed, suggesting a possible dissociation between escalated intake and motivation. However, the present reanalysis clearly differentiates the effects of CRF-R1 and CRF-R2 antagonism between the aVTA and pVTA on binge self-administration (Fig. 4). Within the aVTA, CRF-R2, but not CRF-R1, antagonism prevented increased binge cocaine self-administration, whereas the converse was true of the pVTA.

The distribution of CRF-R1 and CRF-R2 along the rostrocaudal axis of the VTA has not yet been reported, but recent work suggests that CRF-R1 within the pVTA may be more relevant for the initial response to stress, whereas CRF-R2 within the aVTA may be recruited with repeated stress exposure (Holly et al., 2015). Within the locus ceruleus and dorsal raphe nucleus, stress induces internalization of CRF-R1 and externalization of CRF-R2 to the membrane (Reyes et al., 2008; Waselus et al., 2009) and a similar effect may be occurring within the aVTA in combination with recruitment of a phasic aVTA CRF response with repeated stress.

Although CRF actions on VTA CRF-Rs during repeated stress contribute to the development of later maladaptive cocaine selfadministration, the current findings also demonstrate that VTA CRF continues to play a significant role in cocaine seeking after stress. Prior stress increased cocaine seeking $>1$ month after the last defeat (Fig. 6). Because most humans undergo abstinenceeither voluntary or forced-instead of extinction (Katz and Higgins, 2003), the current study attempted to translate the human condition to rats through reexposure to cocaine selfadministration chambers after forced abstinence. Antagonism of either pVTA CRF-R1 or aVTA CRF-R2 after stress-induced neuroadaptations had already occurred prevented augmented cocaine seeking after forced abstinence in previously stressed rats. This parallels the findings of Experiment 2, furthering the hypothesis that there may be rostrocaudal differences in CRF-R expression as a result of stress exposure.

VTA CRF-R1 and CRF-R2 have both been implicated in stressinduced reinstatement to cocaine seeking after extinction (Wang et al., 2007; Blacktop et al., 2011), so it was initially hypothesized that cocaine seeking after forced abstinence in previously stressed animals was serving as an additional stressor, phasically increasing extracellular CRF within the VTA. However, the present results indicate that, although previously stressed animals still had significantly greater CRF tone throughout the VTA compared with previously nonstressed rats, there were no phasic CRF changes in the VTA within either group. This suggests that intra-VTA CRF-R antagonism, rather than preventing any phasic CRF effect, may prevent the increased extracellular tonic CRF from exerting effects, contributing to cocaine seeking after forced abstinence in previously stressed animals. Future work should elucidate a causal, as opposed to a correlational, link between augmented CRF tone and selective changes in expression of CRF within the VTA. Nonetheless, CRF is not the only endogenous ligand for CRF-R1 and CRF-R2 and the urocortin system may contribute to increased cocaine seeking (Ryabinin et al., 2012).

Addiction is a chronic relapsing disorder intricately entwined with stress and characterized by cycles of abstinence/withdrawal followed by reinitiation of drug taking (Koob and Kreek, 2007). In later phases of addiction, negative, as opposed to positive, reinforcement may be a more critical process behind escalated drug taking and seeking behavior (Koob and Le Moal, 2001, 2008). As we demonstrate here, pVTA CRF is significantly different from baseline upon the termination of both acute and repeated social stress, indicating a possible role of pVTA CRF in negative reinforcement. The current series of experiments suggests a critical role of VTA CRF acting on aVTA CRF-R2 and pVTA CRF-R1, not only in stress, but also in escalated cocaine intake and relapse after abstinence. This work complements a growing literature implicating extrahypothalamic CRF, particularly in the extended amygdala, in animal models of escalated drug self-administration (Zhou et al., 1996; Funk et al., 2006; Funk and Koob, 2007; George et al., 2007; Specio et al., 2008; Greenwell et al., 2009).

\section{References}

Blacktop JM, Seubert C, Baker DA, Ferda N, Lee G, Graf EN, Mantsch JR (2011) Augmented cocaine seeking in response to stress or CRF delivered into the ventral tegmental area following long-access self-administration is mediated by CRF receptor type 1 but not CRF receptor type 2. J Neurosci 31:11396-11403. CrossRef Medline

Boyson CO, Holly EN, Shimamoto A, Albrechet-Souza L, Weiner LA, DeBold JF, Miczek KA (2014) Social stress and CRF-dopamine interactions in the VTA: role in long-term escalation of cocaine self-administration. J Neurosci 34:6659-6667. CrossRef Medline

Brischoux F, Chakraborty S, Brierley DI, Ungless MA (2009) Phasic excitation of dopamine neurons in ventral VTA by noxious stimuli. Proc Natl Acad Sci U S A 106:4894-4899. CrossRef Medline

Clinical and Laboratory Standards Institute (2004) Protocols for determination of limits of detection and limits of quantitation, approved guideline. Wayne, PA: CSLI.

Covington HE 3rd, Miczek KA (2001) Repeated social-defeat stress, cocaine or morphine: effects on behavioral sensitization and intravenous cocaine self-administration "binges." Psychopharmacology 158:388-398. CrossRef Medline

Erb S, Shaham Y, Stewart J (1996) Stress reinstates cocaine-seeking behavior after prolonged extinction and a drug-free period. Psychopharmacology 128:408-412. CrossRef Medline

Fallon JH, Moore RY (1978) Catecholamine innervation of the basal forebrain. IV. Topography of the dopamine projection to the basal forebrain and neostriatum. J Comp Neurol 180:545-580. CrossRef Medline

Fiorillo CD, Williams JT (1998) Glutamate mediates an inhibitory postsynaptic potential in dopamine neurons. Nature 394:78-82. CrossRef Medline

Fuchs RA, Branham RK, See RE (2006) Different neural substrates mediate cocaine seeking after abstinence versus extinction training: a critical role for the dorsolateral caudate-putamen. J Neurosci 26:3584-3588. CrossRef Medline

Funk CK, Koob GF (2007) A CRF 2) agonist administered into the central nucleus of the amygdala decreases ethanol self-administration in ethanoldependent rats. Brain Res 1155:172-178. CrossRef Medline

Funk CK, O'Dell LE, Crawford EF, Koob GF (2006) Corticotropin-releasing factor within the central nucleus of the amygdala mediates enhanced ethanol self-administration in withdrawn, ethanol-dependent rats. J Neurosci 26:11324-11332. CrossRef Medline

George O, Ghozland S, Azar MR, Cottone P, Zorrilla EP, Parsons LH, O’Dell LE, Richardson HN, Koob GF (2007) CRF-CRF1 system activation mediates withdrawal-induced increases in nicotine self-administration in nicotine-dependent rats. Proc Natl Acad Sci U S A 104:17198-17203. CrossRef Medline

George O, Sanders C, Freiling J, Grigoryan E, Vu S, Allen CD, Crawford E, Mandyam CD, Koob GF (2012) Recruitment of medial prefrontal cor- 
tex neurons during alcohol withdrawal predicts cognitive impairment and excessive alcohol drinking. Proc Natl Acad Sci U S A 109:1815618161. CrossRef Medline

Greenwell TN, Funk CK, Cottone P, Richardson HN, Chen SA, Rice KC, Zorrilla EP, Koob GF (2009) Corticotropin-releasing factor-1 receptor antagonists decrease heroin self-administration in long- but not shortaccess rats. Addiction Biology 14:130-143. CrossRef Medline

Grieder TE, Herman MA, Contet C, Tan LA, Vargas-Perez H, Cohen A, Chwalek M, Maal-Bared G, Freiling J, Schlosburg JE, Clarke L, Crawford E, Koebel P, Repunte-Canonigo V, Sanna PP, Tapper AR, Roberto M, Kieffer BL, Sawchenko PE, Koob GF, van der Kooy D, GeorgeO (2014) VTACRF neurons mediate the aversive effects of nicotine withdrawal and promote intake escalation. Nat Neurosci 17:1751-1758. CrossRef Medline

Hauser SR, Bracken AL, Deehan GA Jr, Toalston JE, Ding ZM, Truitt WA, Bell RL, McBride WJ, Rodd ZA (2014) Selective breeding for high alcohol preference increases the sensitivity of the posterior VTA to the reinforcing effects of nicotine. Addiction Biology 19:800-811. CrossRef Medline

Hearing MC, See RE, McGinty JF (2008) Relapse to cocaine-seeking increases activity-regulated gene expression differentially in the striatum and cerebral cortex of rats following short or long periods of abstinence. Brain Struct Funct 213:215-227. CrossRef Medline

Henry B, Vale W, Markou A (2006) The effect of lateral septum corticotropin-releasing factor receptor 2 activation on anxiety is modulated by stress. J Neurosci 26:9142-9152. CrossRef Medline

Holly EN, Miczek KA (2016) Ventral tegmental area dopamine revisited: effects of acute and repeated stress. Psychopharmacology 233:163-186. CrossRef Medline

Holly EN, Shimamoto A, Debold JF, Miczek KA (2012) Sex differences in behavioral and neural cross-sensitization and escalated cocaine taking as a result of episodic social defeat stress in rats. Psychopharmacology 224: 179-188. CrossRef Medline

Holly EN, DeBold JF, Miczek KA (2015) Increased mesocorticolimbic dopamine during acute and repeated social defeat stress: modulation by corticotropin releasing factor receptors in the ventral tegmental area. Psychopharmacology 232:4469-4479. CrossRef Medline

Ikemoto S (2007) Dopamine reward circuitry: two projection systems from the ventral midbrain to the nucleus accumbens-olfactory tubercle complex. Brain Res Rev 56:27-78. CrossRef Medline

Ikemoto S, Wise RA (2002) Rewarding effects of the cholinergic agents carbachol and neostigmine in the posterior ventral tegmental area. J Neurosci 22:9895-9904. Medline

Ikemoto S, Murphy JM, McBride WJ (1998) Regional differences within the rat ventral tegmental area for muscimol self-infusions. Pharmacol Biochem Behav 61:87-92. CrossRef Medline

Katz JL, Higgins ST (2003) The validity of the reinstatement model of craving and relapse to drug use. Psychopharmacology 168:21-30. CrossRef Medline

Koob G, Kreek MJ (2007) Stress, dysregulation of drug reward pathways, and the transition to drug dependence. Am J Psychiatry 164:1149-1159. CrossRef Medline

Koob GF, Le Moal M (2001) Drug addiction, dysregulation of reward, and allostasis. Neuropsychopharmacology 24:97-129. CrossRef Medline

Koob GF, Le Moal M (2008) Addiction and the brain antireward system. Annu Rev Psychol 59:29-53. CrossRef Medline

Korotkova TM, Brown RE, Sergeeva OA, Ponomarenko AA, Haas HL (2006) Effects of arousal- and feeding-related neuropeptides on dopaminergic and GABAergic neurons in the ventral tegmental area of the rat. Eur J Neurosci 23:2677-2685. CrossRef Medline

Lammel S, Lim BK, Malenka RC (2014) Reward and aversion in a heterogeneous midbrain dopamine system. Neuropharmacology 76:351-359. CrossRef Medline

Lindvall O, Björklund A (1974) The organization of the ascending catecholamine neuron systems in the rat brain as revealed by the glyoxylic acid fluorescence method. Acta Physiol Scand Suppl 412:1-48.

Miczek KA (1979) A new test for aggression in rats without aversive stimulation: differential effects of d-amphetamine and cocaine. Psychopharmacology 60:253-259. CrossRef Medline

Miczek KA, Mutschler NH (1996) Activational effects of social stress on IV cocaine self-administration in rats. Psychopharmacology 128:256-264. CrossRef Medline

National Research Council (2011) Guide for the care and use of laboratory animals, Ed 8. Washington, DC: National Academies.

Pow DV, Morris JF (1989) Dendrites of hypothalamic magnocellular neu- rons release neurohypophysial peptides by exocytosis. Neuroscience 32 : 435-439. CrossRef Medline

Reichel CM, Bevins RA (2009) Forced abstinence model of relapse to study pharmacological treatments of substance use disorder. Curr Drug Abuse Rev 2:184-194. CrossRef Medline

Reyes BA, Valentino RJ, Van Bockstaele EJ (2008) Stress-induced intracellular trafficking of corticotropin-releasing factor receptors in rat locus coeruleus neurons. Endocrinology 149:122-130. CrossRef Medline

Richardson NR, Roberts DC (1996) Progressive ratio schedules in drug selfadministration studies in rats: a method to evaluate reinforcing efficacy. J Neurosci Methods 66:1-11. CrossRef Medline

Rodd-Henricks ZA, McKinzie DL, Crile RS, Murphy JM, McBride WJ (2000) Regional heterogeneity for the intracranial self-administration of ethanol within the ventral tegmental area of female Wistar rats. Psychopharmacology 149:217-224. CrossRef Medline

Ryabinin AE, Tsoory MM, Kozicz T, Thiele TE, Neufeld-Cohen A, Chen A, Lowery-Gionta EG, Giardino WJ, Kaur S (2012) Urocortins: CRF's siblings and their potential role in anxiety, depression and alcohol drinking behavior. Alcohol 46:349-357. CrossRef Medline

Sanchez-Catalan MJ, Kaufling J, Georges F, Veinante P, Barrot M (2014) The antero-posterior heterogeneity of the ventral tegmental area. Neuroscience 282C:198-216. CrossRef Medline

See RE, Elliott JC, Feltenstein MW (2007) The role of dorsal vs ventral striatal pathways in cocaine-seeking behavior after prolonged abstinence in rats. Psychopharmacology 194:321-331. CrossRef Medline

Sinha R (2008) Chronic stress, drug use, and vulnerability to addiction. Ann N Y Acad Sci 1141:105-130. CrossRef Medline

Specio SE, Wee S, O’Dell LE, Boutrel B, Zorrilla EP, Koob GF (2008) CRF(1) receptor antagonists attenuate escalated cocaine self-administration in rats. Psychopharmacology 196:473-482. CrossRef Medline

Swanson LW (1982) The projections of the ventral tegmental area and adjacent regions: a combined fluorescent retrograde tracer and immunofluorescence study in the rat. Brain Res Bull 9:321-353. CrossRef Medline

Swanson LW, Sawchenko PE, Rivier J, Vale WW (1983) Organization of ovine corticotropin-releasing factor immunoreactive cells and fibers in the rat brain: an immunohistochemical study. Neuroendocrinology 36: 165-186. CrossRef Medline

Tidey JW, Miczek KA (1997) Acquisition of cocaine self-administration after social stress: role of accumbens dopamine. Psychopharmacology 130: 203-212. CrossRef Medline

Tornatzky W, Miczek KA (1993) Long-term impairment of autonomic circadian rhythms after brief intermittent social stress. Physiol Behav 53: 983-993. CrossRef Medline

Ungless MA, Singh V, Crowder TL, Yaka R, Ron D, Bonci A (2003) Corticotropin-releasing factor requires CRF binding protein to potentiate NMDA receptors via CRF receptor 2 in dopamine neurons. Neuron 39: 401-407. CrossRef Medline

van den Pol AN (2012) Neuropeptide transmission in brain circuits. Neuron 76:98-115. CrossRef Medline

Wanat MJ, Hopf FW, Stuber GD, Phillips PE, Bonci A (2008) Corticotropin-releasing factor increases mouse ventral tegmental area dopamine neuron firing through a protein kinase C-dependent enhancement of Ih. J Physiol 586:2157-2170. CrossRef Medline

Wang B, Shaham Y, Zitzman D, Azari S, Wise RA, You ZB (2005) Cocaine experience establishes control of midbrain glutamate and dopamine by corticotropin-releasing factor: a role in stress-induced relapse to drug seeking. J Neurosci 25:5389-5396. CrossRef Medline

Wang B, You ZB, Rice KC, Wise RA (2007) Stress-induced relapse to cocaine seeking: roles for the $\mathrm{CR} F(2)$ receptor and CRF-binding protein in the ventral tegmental area of the rat. Psychopharmacology 193:283-294. CrossRef Medline

Waselus M, Nazzaro C, Valentino RJ, Van Bockstaele EJ (2009) Stress-induced redistribution of corticotropin-releasing factor receptor subtypes in the dorsal raphe nucleus. Biol Psychiatry 66:76-83. CrossRef Medline

Wotjak CT, Landgraf R, Engelmann M (2008) Listening to neuropeptides by microdialysis: echoes and new sounds? Pharmacol Biochem Behav 90:125-134. CrossRef Medline

Zhou Y, Spangler R, LaForge KS, Maggos CE, Ho A, Kreek MJ (1996) Corticotropin-releasing factor and type 1 corticotropin-releasing factor receptor messenger RNAs in rat brain and pituitary during "binge"pattern cocaine administration and chronic withdrawal. J Pharmacol Exp Ther 279:351-358. Medline 